\title{
PERSISTENT ORGANIK POLLUTANTS (POPS) DI BEBERAPA LOKASI PERTANIAN DI INDONESIA (2010)
}

\author{
Heny Puspita Rokhwani, Yunesfi Syofyan Ratnaningsih ${ }^{1}$
}

(Diterima Tanggal........, Disetujui Tanggal..................)

\begin{abstract}
Persistent Organic Compounds (POPs) are the organic substance who was toxic to organism and persistent to the environment. It has bioaccumulation and bio-concentration by food chain process, where is human has high level at the food chain. There is a potential that a human has big concentration on the pollutant by the bioaccumulation process. Exposure by residual of POPs will be serious affected to the human health.

Monitoring on Persistent Organic Pollutants (POPs) and organokhlorine pesticide (OCs) have held on march to August 2010. The sampling location was designed at agriculture area at Medan and Karo for Sumatera Utara, Cianjur and Karawang (Jawa Barat), Dieng (Jawa Tengah) and Batu (Jawa Timur). Matrix samples are water from the river, sediment and soil. monitoring was focused on Aldrin, Heptaklor, Heptaklor epoksid, trans-Klordan, p,p'-DDE, Dieldrin, Endrin, $p, p^{\prime}-D D D, o, p$ '-DDT, and p,p'-DDT. Other compounds (organokhlorine pesticides) as the target on analysis are $\alpha-H C H, \beta-H C H, B H C, \gamma-H C H, \delta-H C H$, Metoksiklor and mirex. Purposes for this monitoring are to identify target, inventory and investigate concentration of POPs on environment. Target compounds have taken from water, soil and sediment sample were extracted by organic solvent, passed to clean up process and analyzed by GCMS QP 2010 used non polar capillary column.

The result show that derivate of $P O P$ s and organokhlorine pesticides such as DDT (p,p'-DDT, o, $p-D D T), D D D$ dan $D D E$ were detected by $0.011 \mathrm{ppb}$ to $0.56 \mathrm{ppb}$ for water sample, $0.23 \mathrm{ppb}$ to $54.9 \mathrm{ppb}$ for soil sample and $0.50 \mathrm{ppb}$ to 18.7 ppb for sediment sample. Other target such as mirex, metoxychlor and endrin were detected by concentration lower than $10 \mathrm{ppb}$.
\end{abstract}

Keywords: Persistent Organic Pollutants (POPs), agriculture area, Indonesia.

\begin{abstract}
ABSTRAK
Senyawa Persistent Organic Pollutants ( POPs ) adalah senyawa organik yang mempunyai sifat toksik bagi mahluk hidup dan dapat bertahan lama di lingkungan (persistent). Senyawa POPs juga memiliki sifat bioakumulasi dan biokonsentrasi melalui rantai makanan, dimana semakin tinggi tingkat kedudukan dalam rantai makanan maka akan menjadi tempat akumulasi yang paling tinggi konsentrasinya, yang kemudian akan memberikan dampak negatif yang serius terhadap kesehatan manusia.

Pemantauan kualitas lingkungan akibat pencemaran kelompok senyawa Persistent Organic Pollutants (POPs) dan pestisida organoklorin (OCs) telah dilakukan di bulan Maret - Agustus 2010. Pengambilan contoh uji dilakukan di sekitar area pertanian atau perkebunan di Medan dan Karo (Sumatera Utara), Cianjur dan Karawang (Jawa Barat), Dieng (Jawa Tengah) dan Batu (Jawa Timur). Jenis contoh uji yang diambil adalah air, tanah dan sedimen.

Senyawa POPs yang dipantau adalah Aldrin, Heptaklor, Heptaklor epoksid, trans-Klordan, p,p'-DDE, Dieldrin, Endrin, p,p'-DDD, o,p'-DDT, dan p,p'-DDT. Senyawaan pestisida jenis organoklorin yang dianalisisis : $\alpha-\mathrm{HCH}$, $\beta-\mathrm{HCH}, \mathrm{BHC}, \gamma-\mathrm{HCH}, \delta-\mathrm{HCH}$, Metoksiklor dan mirex. Tujuan dari pemantauan ini adalah untuk inventarisasi POPs dan OCs di Indonesia, mengetahui jenis dan konsentrasi residu senyawa POPs dan OCs yang terdapat di lingkungan. Senyawa target pada contoh uji air, tanah dan sedimen diekstrak dengan menggunakan pelarut organik, kemudian di clean-up dan dianalisis dengan GCMS QP 2010 menggunakan kolom kapiler non polar.

Hasil analisis menunjukkan bahwa senyawa POPs yang terdeteksi adalah DDT dan turunannya seperti p,p'-DDT, o,p-DDT ,DDD dan DDE. Konsentrasi senyawa DDT dan turunannya yang terdeteksi di air berada pada kisaran $0,011-0.564 \mathrm{ppb}$, di sedimen terdeteksi dengan konsentrasi $0,50 \mathrm{ppb}-18,7 \mathrm{ppb}$ dan tanah terdeteksi dengan konsentrasi $0,23 \mathrm{ppb}-54,9 \mathrm{ppb}$. Sedangkang konsentrasi senyawa target lainnya seperti mirex, endrin dan metoksiklor berada pada konsentrasi $<10 \mathrm{ppb}$.
\end{abstract}

Kata Kunci: Persistent Organic Pollutants (POPs), Lokasi pertanian, Indonesia.

\footnotetext{
${ }^{1}$ Pusat Sarana Pengendalian Dampak Lingkungan-Deputi VII-KLH. Kawasan Puspiptek Gedung 210, J1 Raya Puspiptek, Serpong, Tangerang, Banten, 15310 Indonesia, Telp 021-7560983, email: henypuspita_affan@yahoo.com.
} 


\section{PENDAHULUAN}

UNEP telah menetapkan bahwa senyawa Persistent Organic Pollutants (POPs) merupakan senyawa organik yang bersifat toksik dan dapat bertahan lama di Lingkungan (persisten), sangat mudah berpindah pada rantai yang panjang, bersifat bio-akumulasi dalam rantai makanan yang pada akhirnya akan sampai dalam tubuh hewan manusia dan dapat menimbulkan dampak serius terhadap lingkungan dan kesehatan. (Bouwman, H. (2003)

POPs dan pestisida organokhlorin (OCs) mempunyai sifat persisten tinggi, juga termasuk dalam kelompok senyawa yang dicurigai sebagai penyebab gangguan pada hormon endokrin atau dikenal sebagai Edocrine Disruptor Compounds (EDCs), yang menyebabkan kerusakan pada sistem reproduksi dan sistem kekebalan yang terjadi pada makhluk hidup termasuk janin ((Bouwman, H. (2003)).

Konvensi Stockholm telah menetapkan bahwa bahan kimia POPs terdiri dari dua belas senyawa, dimana sembilan tergolong ke dalam pestisida (Dichloro-DiphenylTrichloroethane/DDT, aldrin, dieldrin, klordan, endrin, heptaklor, heksaklorobenzen, mirex dan toksapen), satu bahan kimia industri (Poly Chlorinated Biphenyl/PCB) dan dua lagi merupakan produk sampingan yang tidak sengaja terbentuk dalam suatu proses (Dioxin dan furan). Meskipun dalam konvensi tersebut telah ditekankan perlunya penghapusan atau pengurangan penggunaan bahan kimia POPs, penggunaan jenis pestisida organokhlorin yang tergolong senyawa POPs untuk peruntukan pembasmian nyamuk penyebab malaria di beberapa negara berkembang masih terjadi. ("Living on Earth: POPsible Nightmare". Living on Earth. 2006. Sementara, pada masa lalu penggunaan senyawa POPs di Indonesia secara luas adalah untuk keperluan pertanian (agriculture), pembasmian hama (public Health) dan lain-lain (industry). Oleh karena itu perlu dilakukan inventarisasi keberadaan senyawa di lingkungan dalam upaya pengelolaannya.

Mengkipun penggunaannya di Indonesia telah dilarang sejak lama, hasil pemantauan yang dilakukan oleh Pusarpedal-KLH sejak tahun 2003 menunjukkan bahwa di beberapa lokasi pertanian di Indonesia residu senyawa POPs dan golongan pestisida Organoklorin (DDT dan turunannya) masih terdeteksi di lingkungan, baik di air, sedimen dan tanah. Hasil Pemantaun pada tahun 2010, masih menunjukan DDT dan turunannya terdeteksi di beberapa lokasi pertanian di Indonesia.

\section{KEBERADAAN POPS DI INDONESIA DAN PERATURAN YANG MENGATUR- NYA}

Di Indonesia penggunaan Pestisida Organokhlorine (OCs) telah lama di larang, dan pada masa lampau umumnya untuk keperluan pertanian seperti memberantas hama dan mengatur atau merangsang pertumbuhan tanaman, untuk keperluan yang berkaitan dengan Kesehatan masyarakat seperti pembasmian vector (nyamuk dan serangga), dan keperluan lain yaitu pengawet bahan-bahan furniture untuk membasmi rayap ataupun keperluan untuk keperluan industri. Menurut Li et al, 2004; pada masa lampau 
DDT pernah di gunakan secara luas oleh 10 negara besar, yang salah satunya adalah Amerika Serikat (1947-1972), sementara itu Li et al, 2004 ; juga menampilkan data 5 besar negara yang terdeteksi adanya DDT dengan konsentrasi cukup besar. Kel5 Negara tersebut adalah Unites stated, India, Negara-negara di Soviet, Indonesia dan China (di tunjukan dalam gambar $1 \mathrm{di}$ bawah ini). Penggunaan umumnya untuk keperluan pertanian, kesehatan Masyarakat dan keperluan lain seperti industri (overall). Kemungkinan terdeteksinya DDT sebagai residu dari pemakaian dimasa lalu atau ada kemungkinan penggunaan secara ilegal.

Karena sifatnya yang persistent di Lingkungan (tidak mudah terpecah dan non degradable), mudah berpindah (dengan media air, udara atau tersedimentasi) serta berpotensi memberi dampak yang serius terhadap kesehatan manusia bila terakumulasi dalam rantai makanan, maka senyawa POPs dan OCs diatur keberadaannya untuk pengendalian terhadap dampak negatifnya. Berikut ini beberapa peraturan terkait dengan senyawa POPs dan OCs di Indonesia;

a. Peraturan Pemerintah republik Indonesia No. 85 tahun 1999; Peraturan tentang pengelolaan Limbah Bahan Beracun Berbahaya (B3), dimana senyawa POPs dan OCs masuk dalam daftar limbah dari bahan kimia kadaluarsa, tumpahan, sisa kegiatan atau buangan produk yang tidak memenuhi spesifikasi.

b. Peraturan Pemerintah Republik Indonesia No.74 tahun 2001; Pengelolaan Bahan Beracun Berbahaya (B3), dimana beberapa senyawa POPs dan OCs masuk dalam Tabel-1 lampiran II sebagai bahan yang di larang dipergunakan. Sedangkan Lindan masuk ke dalam Tabel-2 Lampiran II sebagai bahan yang penggunaannya terbatas.

c. Peraturan Pemerintah Republik Indonesia No. 82 tahun 2001 tentang Kriteria Mutu Air.

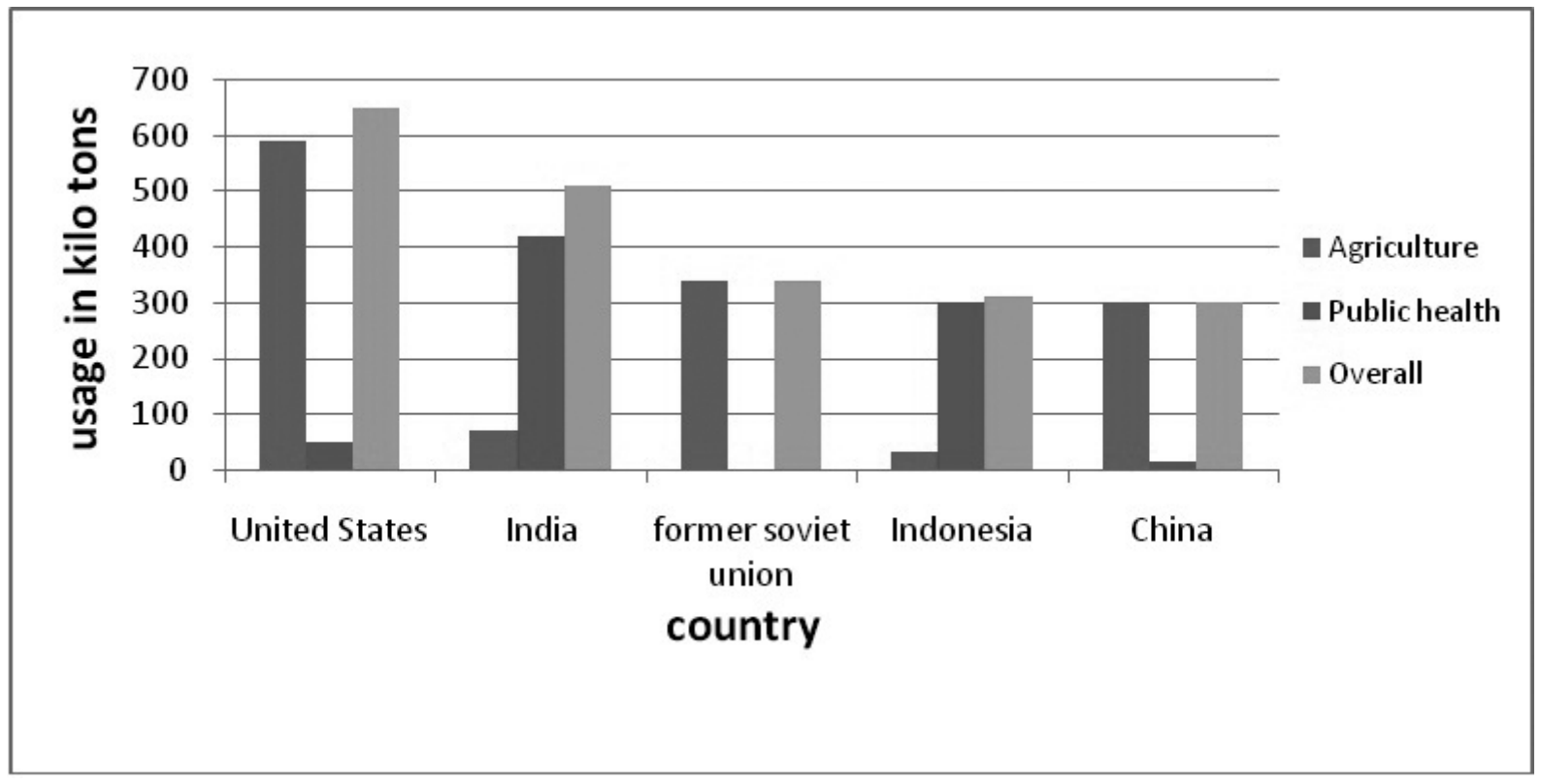

Gambar 1. 5 besar Negara-negara yang pernah penngunakan DDT dimasa lalu dan terdeteksi pada masa kini (Li et al. 2004) 


\section{Pestisida Organokhlorin}

Pestisida Golongan Organokhlorine termasuk dalam kategori POPs. Organoklorin adalah senyawa insektisida yang mengandung sejumlah atom karbon, klor, hidrogen, dan kadangkala oksigen (hidrokarbon klorinat, klorinat organik, insektisida klorinat atau klorinat sintesis). Kemampuan senyawa organoklorin untuk mengendalikan hama serangga baru diketahui sekitar tahun 19391945. Golongan organoklorin mempunyai rumus $\mathrm{CxHyClz}$. Golongan ini dibagi menjadi tiga subgolongan utama, yaitu DDT, BHC, dan siklodiena. Pada umumnya semua subgolongan ini mempunyai sifat-sifat kimia yang hampir sama. Daya larutnya dalam air sangat rendah jika dibandingkan dalam pelarut organik. Dalam keadaan murni, ketiga subgolongan tersebut berbentuk kristal putih atau sedikit kekuning-kuningan.

\section{Dikhloro difenil trikhlorida (DDT)}

Suatu kondensasi Bayer dari kloral dengan klorobenzena di bawah aliran asam sulfat pekat akan menghasilkan senyawa DDT $100 \%$. DDT yang dihasilkan adalah isomer dari p,p-DDT (80\%) dan o,p-DDT (20\%) dan sedikit isomer dari o,o-DDT.
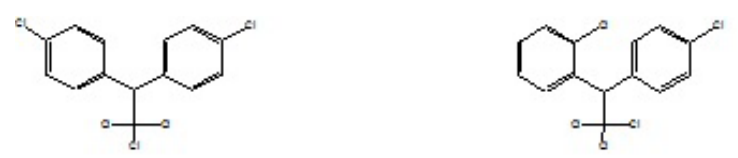

Gambar 2. Struktur p,p dan o,p-DDT

Senyawa ini termasuk ke dalam kelas kimia alifatik difenil yang berarti terdiri atas rantai hidrokarbon alifatik dengan dua gugus fenil yang melekat. DDT merupakan salah satu senyawa sangat nonpolar, ia larut dalam hampir semua bahan pelarut yang nonpolar dan praktis tidak larut dalam air dan etanol dingin. Sifat nonpolar menyebabkan larutan DDT mudah menembus kulit dan masuk ke dalam serangga (Website.organokhorpesticides, diambil tagnggal 3 Maret 2008). Senyawa diklorodifenitrikloroetana (DDT) dan benzalheksaklorida (BHC) merupakan senyawa organoklorin yang pertama kali diketahui memiliki sifat sebagai racun serangga. Senyawa dari golongan ini khususnya DDT telah mencatat sejarah dalam penggunaan pestisida sepanjang abad XX. Paparan DDT pada manusia dengan konsentrasi 10-16 mg/kg akan menyebabkan sakit dengan gejala kejang-kejang (diambil dari web,organokhlorpesticides, 3 Maret 2008). Di lingkungan DDT dapat mengalami dehidroksinasi membentuk diklorodifenildikloroetilen (DDE) dengan katalis garam-garam besi, alumunium, atau kromium.

\section{Dikhloro difenildikhloro etana (DDD)}

Senyawa ini merupakan analog dari DDT yang dikenal dengan nama dagang Rothone ${ }^{\circledR}$. DDD murni berwujud kristal putih, titik lebur $109^{\circ} \mathrm{C}$, dan berbau manis. Daya larut DDD sama dengan DDT tetapi deklorinasinya dalam alkali lebih lambat. DDD adalah hasil metabolisme dari DDT dengan peranan enzim DDT deidroklorinase (DDTase) yang banyak terdapat pada strain lalat yang resisten (Sastroutomo SS, 1992 dalam web yang diambil tahun 2008).

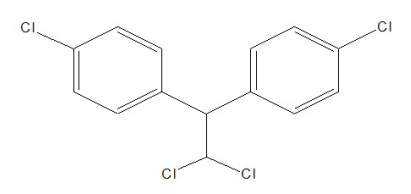

Gambar 3. Struktur senyawa DDD 


\section{Aldrin}

Aldrin memiliki nama kimia 1,2,3,4,10,10-heksakloro-1,4,4a,5,8,8a-heksahidro-1,4-endo, ekso-5,8-dimetanonaftalena atau nama kimia lainnya heksakloroheksahidro-dimetanonaftalena, senyawa ini sangat manjur digunakan untuk membasmi serangga yang hidup di tanah dengan dosis 0.5-5.0 kg/ha. Aldrin memilki bobot molekul $364.96 \mathrm{~g} / \mathrm{mol}$, tekanan uap $2.031 \times 10-5$ $\mathrm{mmHg}\left(20^{\circ} \mathrm{C}\right)$, dan titik leleh $104-107^{\circ} \mathrm{C}$.

Aldrin merupakan racun yang sistematik dan dapat menimbulkan keracunan yang akut ataupun kronis. Selain itu, aldrin juga dapat menimbulkan iritasi pada saluran pernapasan, konvulsi, depresi, dan dapat merusak hati dalam 1 - 4 jam. Bila aldrin dipanaskan maka akan terurai dengan mengeluarkan fosgen dan $\mathrm{HCl}$ yang beracun (Sastroutomo SS 1992 dalam web yang diambil tahun 2008).

\section{METHODOLOGY}

Lokasi pengambilan contoh uji untuk pemantauan POPs tahun 2010 adalah di lokasi pertanian Brastagi sumatera Utara, Lokasi pertanian di Cipanas dan Cianjur, KarawangJawa Barat, pegunungan Dieng-Jawa Tengah dan perkebunan di batu Jawa Timur.

Pengambilan contoh uji air diambil di sungai dengan metoda sesaat menggunakan vandon atau wadah yang terbuat dari stainless teel. Contoh uji di masukan dalam wadah botol kaca berwarna gelap dan di dinginkan pada suhu $4 \AA C$. Sedangkan pengambilan contoh uji sedimen diambil dari sungai dimana dilakukan pengambilan contoh uji air. Pengambilan contoh uji sedimen juga dilakukan dengan alat pengambil contoh uji yang terbuat dari stainless steel (edgman dredge). Dan pengambilan contoh uji tanah dilakukan di Lokasi lahan pertanian pada top soil (tanah di permukaan dengan kedalamam minimal $5 \mathrm{~cm}$ ). Tanah diambil di lima titik kemudian digabungkan berdasarkan kepada Z Pattern Sampling.

Pengujian dilakukan dengan ekstraksi pelarut organik terhadap contoh uji, selanjutnya contoh adalah proses clean-up dengan kolom florisil dan diukur dengan menggunakan Gas Chromatography Spectrometri Massa (GCMS).

Hasil analisis yang keluar dari alat diplotkan pada kurva kalibrasi. kemudian dihitung kembali dengan memperhatikan faktor-faktor yang berpengaruh pada tahapan analisis.

\section{HASIL DAN PEMBAHASAN}

Berdasarkan Peraturan Pemerintah Republik Indonesia No.85 tahun 1999 Tentang Pengelolaan Limbah B3, senyawaan yang tergolong POPs dan OCs tertera dalam daftar lampiran II dan II peraturan tersebut sebagai zat pencemar yang bersifat kronis dan bersifat racun. Sementara nilai baku mutunya ditetapkan sebagai baku mutu TCLP (limbah atau bahan pencemar yang terleaching di lingkungan). Berikut ini kutipan baku mutu TCLP dalam limbah untuk menentukan sifat racunnya untuk beberapa parameter yang tergolong OCs dan POPs: 
Tabel 1. Baku mutu TCLP untuk beberapa parameter POPs dan OCs (PP RI No.85 tahun 1999)

\begin{tabular}{|c|l|c|}
\hline KODE LIMBAH & \multicolumn{1}{|c|}{ PARAMETER } & BAKU MUTU MG/L (PPM) \\
\hline D 4023 & Endrin & 0,02 \\
\hline D 4025 & Heptakhlor + heptakhlor epoxide & 0,008 \\
\hline D 4026 & Hexachlorobenzene & 0,13 \\
\hline D 4030 & Lindane & 0,4 \\
\hline D 4032 & Metoxychlor & 10 \\
\hline D 4001 & Aldrin + Dieldrin & 0,07 \\
\hline D 4008 & Chlordane & 0,03 \\
\hline
\end{tabular}

Hasil pemantauan untuk tahun 2010, konsentrasi yang terdeteksi untuk senyawa OCs yang tergolong POPs adalah DDT dan turunannya. Kisaran konsentrasinya 0,011 ppb sampai dengan 0,56 ppb untuk contoh uji air dan terdeteksi pada lokasi pemantauan di Dieng dan Cianjur. Untuk contoh uji tanah terdeteksi dengan konsentrasi 0,23 ppb sampai dengan 54,9 ppb di tanah perkebunan Batu, terdeteksi hampir disemua lokasi pemantauan.
Untuk contoh uji sedimen terdeteksi dengan konsentrasi 0,50 ppb sampai dengan 18,7 ppb, terdeteksi tertinggi di Medan Sumatera Utara. Bila di bandingkan dengan baku mutu TCLP, konsentrasi yang terdeteksi masih di bawah nilai yang dipersyaratkan. Akan tetapi keberadaannya di lingkungan masih tetap harus di pantau karena sifatnya yang persistent dan bioakumulasi.

Tabel 2. Konsentrasi DDT dan turunannya di air, sedimen dan tanah, tahun 2010 (PusarpedalKLH,2010)

\begin{tabular}{|c|c|c|c|c|c|c|c|c|c|c|c|c|c|c|c|}
\hline \multirow{3}{*}{ Parameter } & \multicolumn{15}{|c|}{ Konsentrasi Tertinggi DDT dan turunannya di air, sedimen dan tanah, Tahun 2010 (ppb) } \\
\hline & \multicolumn{3}{|c|}{ Cianjur } & \multicolumn{3}{|c|}{ medan } & \multicolumn{3}{|c|}{ Karawang } & \multicolumn{3}{|c|}{ Dieng } & \multicolumn{3}{|c|}{ Batu } \\
\hline & Air & Sed & tanah & air & sed & $\operatorname{tanah}$ & Air & tanah & sed & air & tanah & Se,d & air & tanah & sed \\
\hline p.p'-DDD* & 0,012 & $<0,001$ & 5,22 & $<0,001$ & 4,71 & $<0,001$ & $<0,001$ & $<0,001$ & 001 & 0,032 & 1,36 & $<0,001$ & 0,01 & 6,10 & $<0,001$ \\
\hline o.p'-DDD* & $<0,001$ & $<0,001$ & $<0,001$ & $<0,001$ & $<0,001$ & $<0,001$ & $<0,001$ & $<0,001$ & 001 & $<0,001$ & 1,3 & $<0,001$ & 0,01 & $<0,001$ & $<0,001$ \\
\hline p.p'-DDE* & $<0,001$ & 0,50 & 27,2 & $<0,001$ & $<0,001$ & 5,3 & $<0,001$ & 2,1 & 2,61 & 0,11 & 14,6 & 3,1 & $<0,001$ & 54,9 & $<0,001$ \\
\hline o.p'-DDE* & $<0,001$ & $<0,001$ & 14,2 & $<0,001$ & $<0,001$ & $<0,001$ & $<0,001$ & $<0,001$ & $<0,001$ & 001 & $<0,001$ & 0,01 & $<0,001$ & 0,01 & 3,7 \\
\hline p.p'-DDT* & 0,025 & $<0,001$ & 13,9 & $<0,001$ & 18,7 & $<0,001$ & $<0,001$ & 0,23 & 1,51 & 0,02 & $<0,001$ & 0,01 & $<0,001$ & 4,7 & $<0,001$ \\
\hline o.p'-DDT* & 0,013 & $<0,001$ & 8,01 & $<0,001$ & 3,7 & $<0,001$ & $<0,001$ & $<0,001$ & $<0,001$ & 0,56 & 4,1 & 2,9 & 0 & 7,6 & $<0,001$ \\
\hline
\end{tabular}




\section{Konsentrasi POPs dan OCs dalam Tanah, Tahun 2010}

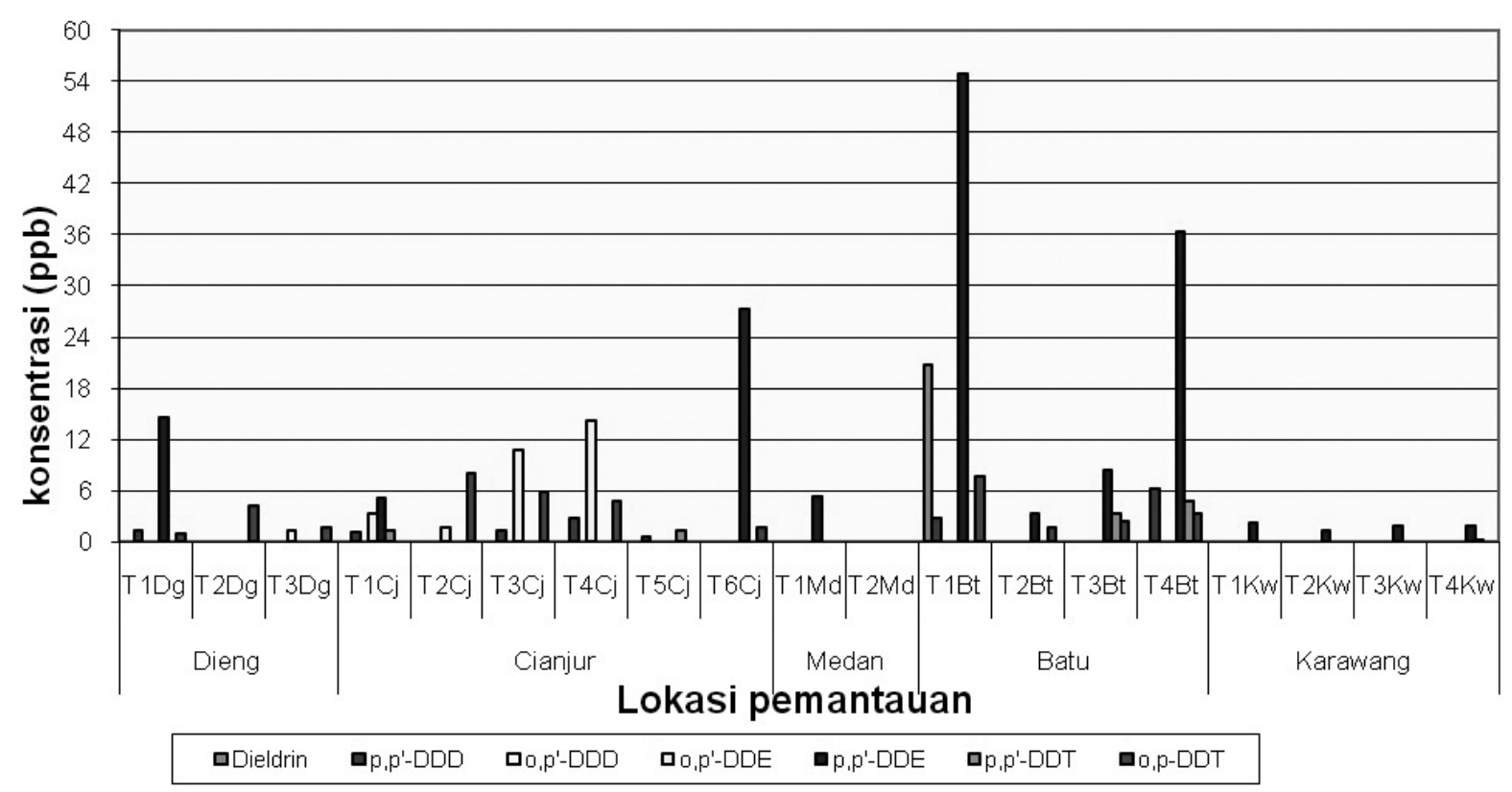

Gambar 2. Konsentrasi POPs dan OCs dalam tanah, tahun 2010

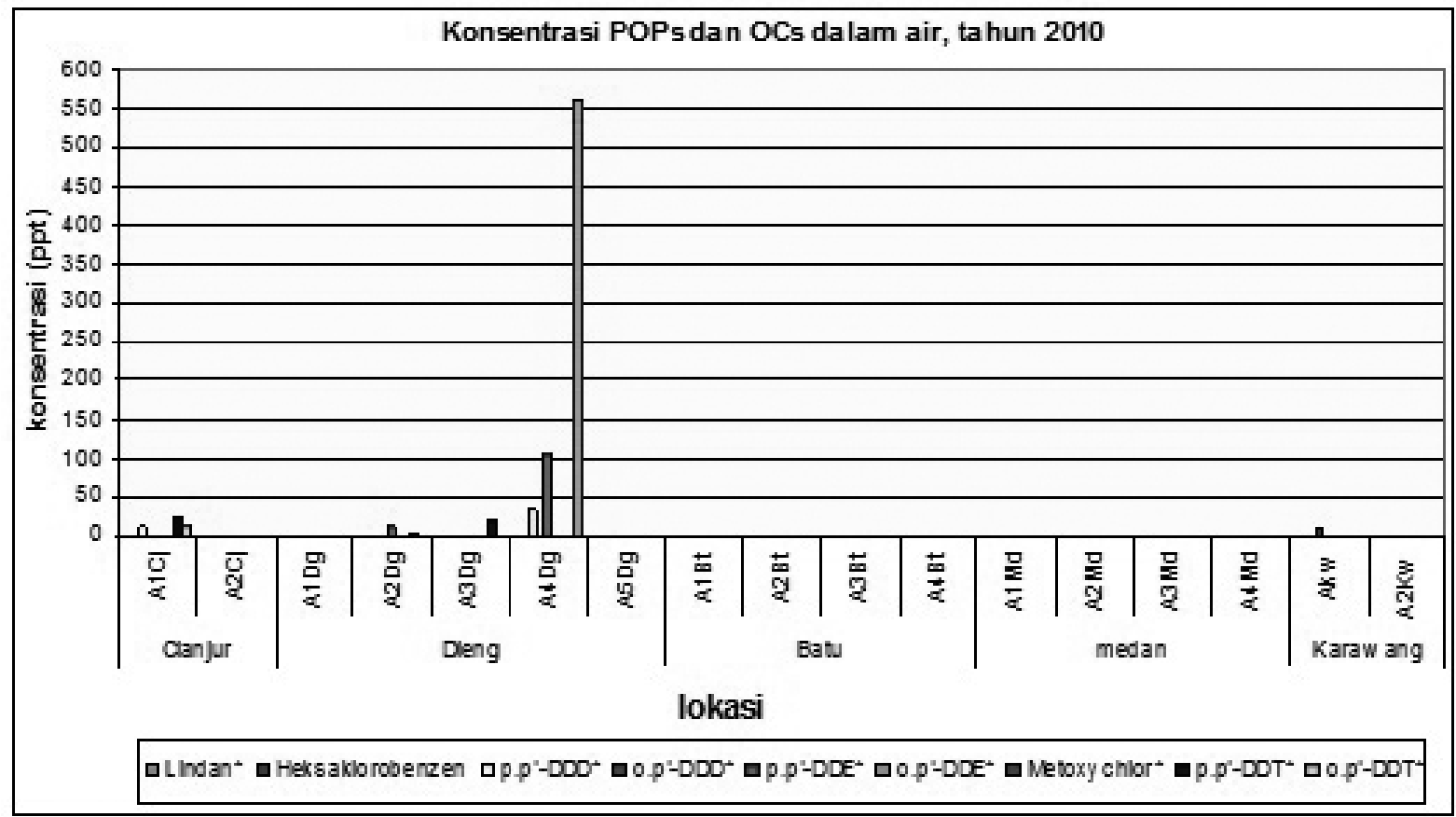

Gambar 3. Konsentrasi POPs dan OCs dalam air, tahun 2010

Dari gambar 3, DDT dan turunannya terdeteksi dengan konsentrasi Part pertriliun (ppt), terdeteksi tertinggi di Dieng dan Cianjur. Di Dieng lokasi pengambilan contoh uji adalah sumber mata air Sahang dan Tuk Bimalukar. Lokasi mata air ini di bawah lokasi pertanian, sehingga memungkinkan terjadinya pencemaran karena semua aliran air terbawa sampai ke mata air ini. 


\section{KESIMPULAN}

Beberapa senyawa POPs dan organoklorin (DDT dan turunannya) untuk contoh uji tanah dan sedimen masih terdeteksi di lingkungan dengan kisaran konsentrasi 0,23 sampai dengan 54,9 ppb, sedangkan untuk contoh uji air terdeteksi dengan konsentrasi 0,011 ppb sampai dengan 0,56 ppb. Dengan terdeteksinya Pestisida organokhlorin di beberapa lokasi pertanian di Indonesia, keberadaan residu ini harus diperhatikan dan perlu di lakukan pengujian selanjutnya tentang kualitas lingkungan di lokasi pertanian di Indonesia, guna mengetahui dampak lanjutan dari keberadaan residu POPs dan pestisida organokhlorin.

\section{DAFTAR PUSTAKA}

(1) Bouwman, H., "POPs in southern Africa", Handbook of Environmental Chemistry. 2003 Vol. 3O: Persistent Organic Pollutants, pp. 297-320.

(2) Mangala, Y. " POPs in Sea food of China-Review. China University of Geoscience of Wuhan.2009

(3) "Living on Earth: POPsible Nightmare". Living on Earth. 2006. http://www.loe.org/shows/ segments.htm?programID=06-P13$00050 \&$ segmentID $=2$. Retrieved 2007-09-16.)
(4) The United Nation University (UNU) International Symposium on Industries and EDC Pollution.2001. Environmental Monitoring and Governance EDCs in East Asian Coastal Hydrosphere.KORDI Korea.

(5) The United Nation University (UNU) Environmental Monitoring and Governance EDCs in East Asian Coastal Hydrosphere. 1999. Manual for sample collection and Analysis. Japan.

(6) Gunlazuardi, J,.1992. DDT and residues in the Yogyakarta and Bali environment: A monitoring survey in soil, sediment, water, vegetables and fish samples. Pesticides Residues in relation to crop production increment. NODAI Japan.

(7) B Byron A. 1996. Aquatic Ecosystem Contamination and Rivererine Flux of Persistent organic Pollutants (POPs) to Coastal Seas in the Asia-Pasific Region. Canada.

(9) Pusarpedal-KLH. 2010, Pemantauan Persistent Organic Pollutants (POPs) di Indonesia Tahun 2010.

(10) Website Persistent Organic Pollutants; A Global Issue, A Global response, di kutip pada tanggal 3 September 2010

(11) Diambil dari Web; www..pops.int, di ambil pada Septemebr 2010 